\title{
Progressive modulation of the human olfactory bulb transcriptome during Alzheimer"s disease evolution: novel insights into the olfactory signaling across proteinopathies
}

\author{
Mercedes Lachen-Montes ${ }^{1,2}$, María Victoria Zelaya ${ }^{1,2,3}$, Víctor Segura2,4, Joaquín \\ Fernández-Irigoyen ${ }^{1,2,5, *}$ and Enrique Santamaría ${ }^{1,2,5, *}$ \\ ${ }^{1}$ Clinical Neuroproteomics Group, Navarrabiomed, Departamento de Salud, Universidad Pública de Navarra, Pamplona, Spain \\ ${ }^{2}$ IDISNA, Navarra Institute for Health Research, Pamplona, Spain \\ ${ }^{3}$ Pathological Anatomy Department, Navarra Hospital Complex, Pamplona, Spain \\ ${ }^{4}$ Bioinformatics Unit, Center for Applied Medical Research, University of Navarra, Pamplona, Spain \\ ${ }^{5}$ Proteored-ISCIII, Proteomics Unit, Navarrabiomed, Departamento de Salud, Universidad Pública de Navarra, Pamplona, Spain \\ *These authors share senior authorship
}

Correspondence to: Enrique Santamaría, email: esantamma@navarra.es

Keywords: Alzheimer, neurodegeneration, dementia, olfactory bulb, transcriptomics

Received: January 21, $2017 \quad$ Accepted: May 07, $2017 \quad$ Published: May 23, 2017

Copyright: Lachen-Montes et al. This is an open-access article distributed under the terms of the Creative Commons Attribution License 3.0 (CC BY 3.0), which permits unrestricted use, distribution, and reproduction in any medium, provided the original author and source are credited.

\section{ABSTRACT}

Alzheimer's disease (AD) is characterized by progressive dementia, initially presenting olfactory dysfunction. Despite the olfactory bulb (OB) is the first central structure of the olfactory pathway, we lack a complete molecular characterization of the transcriptional events that occurs in this olfactory area during AD progression. To address this gap in knowledge, we have assessed the genome-wide expression in postmortem OBs from subjects with varying degree of AD pathology. A stagedependent deregulation of specific pathways was observed, revealing transmembrane transport, and neuroinflammation as part of the functional modules that are disrupted across AD grading. Potential drivers of neurodegeneration predicted by networkdriven transcriptomics were monitored across different types of dementia, including progressive supranuclear palsy (PSP), mixed dementia, and frontotemporal lobar degeneration (FTLD). Epidermal growth factor receptor (EGFR) expression was significantly increased in the $O B$ of $A D$ and mixed dementia subjects. Moreover, a significant increment in the activation of signal transducer and activator of transcription 3 (STAT3) was exclusively detected in advanced AD stages, whereas total STAT3 levels were specifically overexpressed in mixed dementia. Furthermore, transcription factors deregulated in the OB of mixed dementia subjects such as CAMP Responsive Element Binding Protein 1 (CREB1) and AP-1 Transcription Factor Subunit (c-Jun) were not differentially modulated at olfactory level across AD grading. On the other hand, olfactory expression of this signal transducer panel was unchanged in PSP and FTLD subjects. Taken together, this study unveils cross-disease similarities and differences for specific signal transducers, providing mechanistic clues to the intriguing divergence of AD pathology across proteinopathies. 


\section{INTRODUCTION}

Although olfactory involvement may also appear in healthy non-demented elderly subjects [1], olfactory dysfunction is present in up to $90 \%$ of $\mathrm{AD}$ patients [2]. Some studies suggest that olfactory dysfunction is an early event of $\mathrm{AD}$, preceding the appearance of typical $\mathrm{AD}$ symptoms, such as memory loss, and dementia. The olfactory bulb $(\mathrm{OB})$ is the first central structure of the olfactory pathway in the brain [3]. An OB atrophy and a significant reduction in olfactory performance have been detected in AD respect to control subjects using MRI and PET technologies $[4,5]$. From a neuropathological point of view, olfactory centres are involved in early Braak stages [6], and OB pathology correlates with cortical AD pathology [7-9]. In view of these data, an in depth biochemical characterization of the neurodegeneration that occurs in the $\mathrm{OB}$ is mandatory as a first step for understanding early smell impairment in AD. Although neuroanatomical, volumetric, and histological approaches have been the gold standard techniques employed to characterize the $\mathrm{OB}$ functionality, little attention has been focused specifically on the molecular composition of the $\mathrm{OB}$ from the perspective of high throughput molecular technologies $[10,11]$. Different transcriptomic studies have been attempted to discover novel regulatory mechanisms associated with $\mathrm{AD}$ pathogenesis in brain areas differentially affected by the disease [12]. Nevertheless, no study to date has addressed whether specific patterns of gene expression is associated to the development of human AD-related pathology at olfactory level in a stage-dependent manner. We consider that deciphering the progressive transcriptome-wide alterations that occurs in the OB derived from human $\mathrm{AD}$ cases with different Braak staging, might help develop early diagnosis and identify potential therapeutic targets for $\mathrm{AD}$. In this study, we have analyzed the progressive modulation of the $\mathrm{OB}$ transcriptome across neuropathological stages of $\mathrm{AD}$, in order to increase our knowledge about the pathophysiological mechanisms that are disturbed during the $\mathrm{AD}$ neurodegeneration in the OB. 249 differential genes were detected between controls and $\mathrm{AD}$-related phenotypes, pinpointing specific pathways, gene interaction networks, and potential novel therapeutic targets that are modulated in specific $A D$ stages. Interestingly, the $\mathrm{OB}$ transcriptome exploration in parallel with a cross-disease analysis including different proteinopathies, has revealed distinct modulation of specific signal transducers, providing new avenues of research into the role of olfactory signaling across different types of dementias.

\section{RESULTS AND DISCUSSION}

During the last decade, gene expression profiling of postmortem tissue has greatly increased our knowledge about the pathophysiological mechanisms that occur in affected brain structures during AD progression [12]. With the aim to identify downstream aberrant gene expression related to beta-amyloid and Tau deposits across $\mathrm{AD}$ phenotypes, the temporal lobe-hippocampus and the frontal-prefrontal cortex has been the most studied areas [12-16]. However, loss of smell is involved in early stages of $\mathrm{AD}$, partially due to an imbalance in the OB functionality [17]. Albeit olfactory impairment is considered an important clinical marker and predictor of AD progression [18], the mechanisms governing this dysfunction are still poorly understood. Transcriptome profiling has revealed multiple metabolic alterations in the OB of a rat $\mathrm{AD}$ model [19], however, the progression of the disease in rodent models does not correlate well with human AD [20], being necessary genome-wide studies in human olfactory tissue with neuropathologically welldefined AD-associated changes (Figure 1).

\section{OB transcriptome dynamics during AD progression}

The immunohistochemical study of $\beta$-amyloid and phospho-Tau protein in the cases included in this study (Table 1), allowed us to confirm the presence of neuropathological proteins in the $\mathrm{OB}$ of subjects with distinct stages of $\mathrm{AD}$ (Figure 2), confirming the involvement of OB in pre-clinical stages of the disease. To further understand the olfactory molecular background contributing to the progression of $\mathrm{AD}$, we have performed a differential $\mathrm{OB}$ transcriptome analysis in order to detect early and stage-dependent molecular events underlying the progression of the disease at olfactory level (Figure 1). As shown in Figure 3, 103, 78, and 105 differentially expressed protein-coding genes were detected in initial, intermediate, and advanced AD stages respectively (Supplementary Table 2). In our sample set, the distribution between up-regulated and downregulated protein coding-genes was very similar across $\mathrm{AD}$ grading (Figure $3 \mathrm{~A}$ ). As expected, we detected a substantial heterogeneity within the same Braak staging. This may be due to unpredictable confounders such as clinical, environmental, behavioral and agonal factors (i.e medication, substance abuse and health status prior to death) [21]. However, 10 genes were modulated across all stages (Figure 3B), suggesting a potential role during AD progression (Table 2), although we can not discard that this subset of olfactory genes may be also primary related to the neurodegenerative process that occur in other neurodegenerative diseases with common smell impairment. Some of these genes are involved in synaptic plasticity (EGFLAM), zinc transporter (SLC39A11), retinoid carrier ( $L C N 10)$, and sodium and carbohydrate transport (SLC5A11). Other differential expressed genes overlapped between initial-intermediate stages, intermediate-advanced stages, and initial-advanced stages 
(Table 2). We have investigated whether the differential OB transcriptomic fingerprint has been partially reflected in previous transcriptomic studies performed in different brain structures across AD pathology [15, 22-27]. According to our integrative meta-analysis (Supplementary Table 3), most of the differential OB genes have not been previously proposed as differential molecular features in hippocampal structures affected by the disease, serving as a foundation for new areas of investigation into the role of olfactory signaling in human AD. However, due to the OB pathology correlates with cortical AD pathology [7-9], we compared our differential gene sets with the differential expressed genome that previously showed significant expression correlation to Braak stage and cerebral atrophy in prefrontal cortex from AD subjects [16]. Thirteen $\mathrm{OB}$ differential genes in initial stages (KLC1, RAB7L1, C8orf46, GRM8, DCC, TMEM9, DDA1, HPCAL1, C15orf37, SYT13, VIP, RGS4, SST), seven differential expressed OB genes in intermediate stages (OR2T2, LOR, DCLRE1C, HMOX2, UBE2NL, $S Y T 13)$, and eight differential OB genes in advanced stages (ZNF443, PHF17, CEP68, UIMC1, SMAD5, $E L F 1, P T P N 2, C A S P 1)$ present a significant expression correlation to Braak staging at cortical level [16]. Moreover, twenty OB early-deregulated genes (C15orf37, C8orf46, DCC, DDA1, GIMAP7, GRM8, HPCAL1, KLC1, PDE10A, RASAL1, RGS4, SST,TMEM204, TMEM9, VIP, TMSB15B, RAB7L1, SYT13, EGFLAM, SLC39A11), sixteen OB intermediate-affected genes (TMSB15B, RAB7L1, SYT13, ESAM, EGFLAM, SLC39A11, CTXN3, DCLRE1C, GTF3C6, HLA-DRA, HMOX2, LOR, NBPF1, OR2T2, RASL11B, SNRPN), and fifteen OB advanced-deregulated genes (EGFLAM, SLC39A11, ESAM, CASP1, CD58, CEP68, CHRM4, ELF1, PHF17, PTPN2, SERPINH1, SMAD5, TUBA1A, UIMC1, ZNF443) showed a good correlation with cerebral atrophy [16].

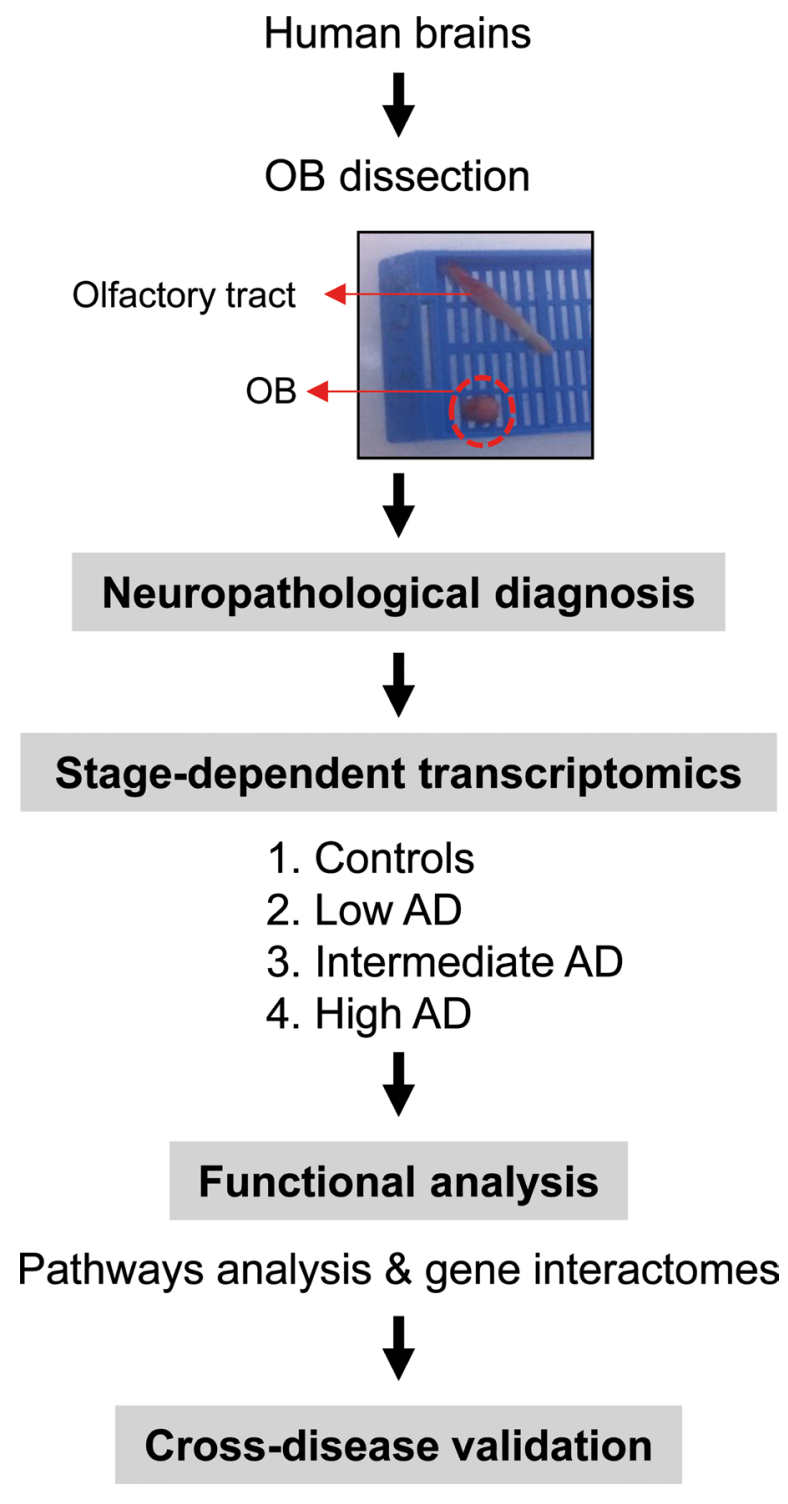

Figure 1: An overview of the workflow used for the characterization of OB transcriptome during AD evolution. 
Table 1: Summary of selected cases included in this study

\begin{tabular}{|c|c|c|c|c|c|c|c|c|c|}
\hline \multirow[b]{2}{*}{ Cases } & \multirow[b]{2}{*}{ age } & \multicolumn{3}{|c|}{ Duration PMI } & \multirow{2}{*}{$\begin{array}{c}\text { Pathological diagnosis } \\
\text { NIA-AA criteria }\end{array}$} & \multirow{2}{*}{$\frac{\text { IHQ: }}{\text { MP }}$} & \multirow{2}{*}{$\frac{\beta A \text { in } \mathbf{O B}}{\mathrm{DP}}$} & \multicolumn{2}{|c|}{ IHQ: TAU in OB } \\
\hline & & $\operatorname{sex}$ & (years) & (hours) & & & & Tangles & neurites \\
\hline \multicolumn{10}{|l|}{ Control } \\
\hline $\mathrm{C} 1$ & 72 & M & & 9 & $\begin{array}{c}\text { Thal } 1 \text { Cerad } 1 \text { no tau } \\
\text { deposit }\end{array}$ & - & - & - & + \\
\hline $\mathrm{C} 2$ & 103 & M & & 3 & $\begin{array}{c}\text { No protein } \\
\text { deposit+vascular } \\
\text { disease }\end{array}$ & - & - & - & + \\
\hline $\mathrm{C} 3$ & 81 & $\mathrm{~F}$ & & 3.3 & $\begin{array}{c}\text { PART (Braak } \\
\text { I)+vascular disase }\end{array}$ & - & - & - & + \\
\hline C4 & 61 & M & & 8 & PART (Braak I) & - & - & + & - \\
\hline \multicolumn{10}{|l|}{ Low AD } \\
\hline I1 & 88 & M & 1 & 3.45 & $\mathrm{AD}(\mathrm{A} 2 \mathrm{~B} 1 \mathrm{C} 2)$ & ++ & + & ++ & ++ \\
\hline $\mathrm{I} 2$ & 85 & $\mathrm{~F}$ & 8 & 2 & $\mathrm{AD}(\mathrm{A} 2 \mathrm{~B} 1 \mathrm{C} 1)$ & - & - & + & + \\
\hline $\mathrm{I} 3$ & 80 & M & 5 & 3 & $\mathrm{AD}(\mathrm{A} 2 \mathrm{~B} 1 \mathrm{C} 1)$ & ++ & ++ & ++ & +++ \\
\hline I4 & 75 & $\mathrm{~F}$ & n.d & 6 & $\mathrm{AD}(\mathrm{A} 1 \mathrm{~B} 1 \mathrm{C} 1)$ & - & - & + & + \\
\hline $\mathrm{I} 5$ & 72 & $\mathrm{~F}$ & n.d & 4 & $\mathrm{AD}(\mathrm{A} 1 \mathrm{~B} 1 \mathrm{C} 1)$ & - & - & + & + \\
\hline \multicolumn{10}{|c|}{$\begin{array}{c}\text { intermediate } \\
\text { AD }\end{array}$} \\
\hline M1 & 85 & M & 12 & 3.3 & $\mathrm{AD}(\mathrm{A} 2 \mathrm{~B} 2 \mathrm{C} 2)$ & - & + & +++ & +++ \\
\hline M2 & 97 & $\mathrm{~F}$ & 9 & n.d & $\mathrm{AD}(\mathrm{A} 2 \mathrm{~B} 2 \mathrm{C} 2)$ & n.d & n.d & n.d & n.d \\
\hline M3 & 77 & M & 17 & 1.5 & $\mathrm{AD}(\mathrm{A} 2 \mathrm{~B} 2 \mathrm{C} 1)$ & - & - & ++ & ++ \\
\hline M4 & 86 & $\mathrm{~F}$ & 9 & 3 & $\mathrm{AD}(\mathrm{A} 2 \mathrm{~B} 2 \mathrm{C} 2)$ & - & + & ++ & ++ \\
\hline \multicolumn{10}{|c|}{ High AD } \\
\hline A1 & 77 & $\mathrm{~F}$ & 16 & 4 & $\mathrm{AD}(\mathrm{A} 2 \mathrm{~B} 3 \mathrm{C} 3)$ & + & +++ & +++ & +++ \\
\hline $\mathrm{A} 2$ & 70 & M & 4 & 2.5 & $\mathrm{AD}(\mathrm{A} 3 \mathrm{~B} 3 \mathrm{C} 3)$ & ++ & +++ & ++ & +++ \\
\hline A3 & 89 & M & 13 & 3 & $\mathrm{AD}(\mathrm{A} 2 \mathrm{~B} 3 \mathrm{C} 3)$ & + & +++ & +++ & +++ \\
\hline A4 & 86 & M & 8 & 2.5 & $\mathrm{AD}(\mathrm{A} 3 \mathrm{~B} 3 \mathrm{C} 3)$ & + & - & + & ++ \\
\hline A5 & 93 & M & 3 & 2.4 & $\mathrm{AD}(\mathrm{A} 3 \mathrm{~B} 3 \mathrm{C} 3)$ & + & +++ & +++ & +++ \\
\hline
\end{tabular}

The neuropathological assessment was performed according to Thal phases, adapted CERAD score, NIA-AA guidelines and PART criteria. A $\beta$ immunopositivity was scored on a 4-tiered scale as: $(-)$ negative, $(+) 1-2$ isolated A $\beta$ depositions, $(++)$ 3-4A $\beta$ depositions, and $(+++)>4 \mathrm{~A} \beta$ depositions. Graduation of phospho-TAU deposit: $(-)$ negative + : low; ++ : intermediate; +++ high. PMI: post-mortem interval; n.d: not determined; MP: Mature plaques; DP: Diffuse plaques.

Although our stage-dependent analysis presents a limited number of study population, these data shed new light on the potential coordinated regulation of specific gene modules across AD-related brain structures, reinforcing the molecular correlation between $\mathrm{OB}$ and cortical AD pathology beyond the presence and distribution of betaamyloid and phospho-Tau protein [7-9]. Using data mining-based methods for proteome-scale protein-protein interaction predictions [28], we have generated the potential interactome for human APP ( $\beta$-amyloid precursor protein) and Tau protein (Supplementary Table 4), detecting some OB differentially expressed proteincoding genes as potential APP and/or Tau interactors. Specifically, differentially expressed genes in initial stages like RASAL1, TUBB $4 A$, and $B T K$ genes are potential APP interactors, whereas MAPK8IP1, and HSPA1B genes (deregulated in advanced stages) may be potential Tau interactors. Although these predictive assumptions should be experimentally validated, this information may be useful to generate new working hypothesis to clarify the relationship between both neuropathologic substrates in AD at olfactory level. KLCl gene (Kinesin 2) is a common interactor between both neuropathological substrates (Supplementary Table 4). Moreover, RASAL1, $T U B B 4 A$, and $K L C 1$ are also deregulated in cortical areas from $\mathrm{AD}$ patients [24, 27], being $K L C 1$ a modifier of the beta-amyloid accumulation [29]. Interestingly, kinesin 2 protein levels were significantly increased in the $\mathrm{OB}$ from initial and advanced AD stages (Supplementary Figure 1). In addition, $H S P A 1 B$ gene (up-regulated in advanced AD at the level of $\mathrm{OB}$ ) is also up-regulated at protein level in hippocampus from $\mathrm{AD}$ subjects [30]. RASAL1 and $T U B B 4 A$ genes (up-regulated in initial $\mathrm{AD}$ at the level of $\mathrm{OB})$ are down-regulated in hippocampal proteome at all pathologic stages of $\mathrm{AD}[30]$. All these evidences suggest that $\mathrm{AD}$ pathology modulates the gene/protein expression 
Table 2: Common differentially expressed genes across AD staging

\begin{tabular}{|c|c|c|c|c|c|c|c|}
\hline \multirow{2}{*}{ Gene name } & \multirow{2}{*}{ Gene description } & \multicolumn{2}{|c|}{ LOW AD } & \multicolumn{2}{|c|}{ INTERMEDIATE AD } & \multicolumn{2}{|c|}{ HIGH AD } \\
\hline & & p-Val & FC & p-Val & FC & p-Val & FC \\
\hline EGFLAM & EGF-like, fibronectin type III and laminin G domains & 0.002 & 0.48 & 0.003 & 0.48 & 0.009 & 0.55 \\
\hline LOC391636 & chromosome 9 open reading frame 78 pseudogene & 0.000 & 0.55 & 0.003 & 0.62 & 0.000 & 0.57 \\
\hline RN5S344 & RNA, 5S ribosomal 344 & 0.003 & 0.60 & 0.003 & 0.59 & 0.000 & 0.41 \\
\hline SCARNA2 & small Cajal body-specific RNA 2 & 0.004 & 0.72 & 0.002 & 0.68 & 0.010 & 0.25 \\
\hline FLJ39739 & uncharacterized FLJ39739 & 0.007 & 1.33 & 0.005 & 1.37 & 0.004 & 1.37 \\
\hline MRPL23-AS1 & MRPL23 antisense RNA 1 (non-protein coding) & 0.004 & 1.34 & 0.009 & 1.32 & 0.000 & 1.53 \\
\hline SLC39A11 & solute carrier family 39 (metal ion transporter), member 11 & 0.002 & 1.54 & 0.001 & 1.70 & 0.000 & 1.98 \\
\hline LCN10 & lipocalin 10 & 0.009 & 1.61 & 0.002 & 1.82 & 0.000 & 2.00 \\
\hline CCHCR1 & coiled-coil alpha-helical rod protein 1 & 0.000 & 1.74 & 0.004 & 1.48 & 0.004 & 1.46 \\
\hline SLC5A11 & solute carrier family 5 (sodium/glucose cotransporter), member 11 & 0.001 & 2.30 & 0.002 & 2.30 & 0.010 & 1.89 \\
\hline TMSB15B & thymosin beta $15 \mathrm{~B}$ & 0.006 & 0.72 & 0.006 & 0.71 & n.s & n.s \\
\hline SLIT3 & slit homolog 3 (Drosophila) & 0.005 & 1.46 & 0.008 & 1.45 & n.s & n.s \\
\hline RNU7-76P & RNA, U7 small nuclear 76 pseudogene & 0.003 & 1.54 & 0.010 & 1.47 & n.s & n.s \\
\hline HCRTR1 & hypocretin (orexin) receptor 1 & 0.003 & 1.55 & 0.007 & 1.51 & n.s & n.s \\
\hline TMEM186 & transmembrane protein 186 & 0.006 & 1.55 & 0.008 & 1.55 & n.s & n.s \\
\hline RAB7L1 & RAB7, member RAS oncogene family-like 1 & 0.003 & 1.58 & 0.007 & 1.52 & n.s & n.s \\
\hline SYT13 & synaptotagmin XIII & 0.002 & 1.74 & 0.010 & 1.57 & n.s & n.s \\
\hline SNORD116-27 & small nucleolar RNA, C/D box 116-27 & n.s & n.s & 0.000 & 0.42 & 0.003 & 0.53 \\
\hline YTHDC1 & YTH domain containing 1 & n.s & n.s & 0.008 & 0.56 & 0.006 & 0.56 \\
\hline TREX2 & three prime repair exonuclease 2 & n.s & n.s & 0.002 & 0.59 & 0.002 & 0.60 \\
\hline TK2 & thymidine kinase 2 , mitochondrial & n.s & n.s & 0.001 & 0.61 & 0.007 & 0.68 \\
\hline IP6K3 & inositol hexakisphosphate kinase 3 & n.s & n.s & 0.004 & 1.40 & 0.004 & 1.38 \\
\hline ESAM & endothelial cell adhesion molecule & n.s & n.s & 0.006 & 1.44 & 0.005 & 1.44 \\
\hline RRP7B & ribosomal RNA processing 7 homolog B (S. cerevisiae) & 0.006 & 0.20 & n.s & n.s & 0.001 & 0.11 \\
\hline SNORA36B & small nucleolar RNA, H/ACA box 36B & 0.001 & 0.36 & n.s & n.s & 0.001 & 0.38 \\
\hline ZNF45 & zinc finger protein 45 & 0.009 & 0.73 & n.s & n.s & 0.004 & 0.70 \\
\hline PPP1R13L & protein phosphatase 1 , regulatory subunit 13 like & 0.006 & 1.34 & n.s & n.s & 0.002 & 1.40 \\
\hline
\end{tabular}

of most APP and Tau interactors mentioned in this study in a spatial and stage-dependent manner across AD brains.

Although the analysis of the OB transcriptome provides a unique window into their biochemistry and dysfunction across AD stages, there are potential limitations of our study that warrant discussion. We have processed all cellular layers present in the bulk $\mathrm{OB}$, giving novel insight into the gene-expression in this olfactory area. However, the OB is composed by intermixed multiple cell types with intricate architecture and connectivity [31], and information about specific-cell types where mRNAs originated from is lost in our dataset. The implementation of novel workflows that allow the exploration of olfactory cell-type specific transcriptomes [32] would complement the output of our nonbiased profiling of the $\mathrm{OB}$ transcriptome, minimizing the effect of multiple neuronal microenvironments, and deciphering the specific role of each olfactory neuronal population during AD progression.

\section{Progressive modulation of olfactory pathways across AD staging}

To obtain a functional genomic perspective, differential transcriptomes were analyzed for higher-level organization of genes into common biological pathways using the Reactome database [33] (Supplementary Table 5).
As shown in Figure 4, our results point out a stagedependent deregulation of specific pathways. Gene clusters involved in hemostasis, metabolism of carbohydrates, and metabolism of proteins were mapped across AD stages (Figure 4A), confirming previous observations obtained at protein level using proteomic workflows [34]. Moreover, a de-regulation of genes involved in signal transduction, immune system, and molecular transport was also evidenced across AD staging (Figure 4A), reinforcing the idea that cellular signaling and neuroinflammation are common driving forces of AD pathology across brain structures [12]. Gastrin-CREB signaling is involved in neurogenesis and cognitive impairment at hippocampal level [35], suggesting that the slight alteration in this pathway in initial-intermediate stages (Figure 4B) might play a role in the disruption of olfactory neurogenesis that occur in $\mathrm{AD}$ [36]. In addition, OB HLA-DR genes involved in $\mathrm{MHC}$ class II presentation pathway were up-regulated in intermediate stages (Figure 4B), in accordance with previous transcriptomic experiments performed in cortical structures from AD patients [16, 24, 27]. In line with these findings, an increase in HLA-DR immunopositive microglia across all layers of the cortex has been detected in post-mortem $\mathrm{AD}$ brains [37]. A deregulation of sensory perception of smell has been proposed from transcriptomic information extracted from prefrontal cortex derived from AD subjects [16]. Accordingly, olfactory receptor 
(OR) gene dysregulation has been demonstrated in entorhinal and frontal cortex during AD progression [38]. In our case, we found several de-regulated OR genes during AD progression at the level of OB (Figure 4B). In particular, OR5M1, and OR2T2 genes were downregulated in intermediate stages, while OR2T8, and OR6J1 genes were over-expressed in advanced stages (Supplementary Table 2). These data suggest that the presence of neuropathological substrates at the level of OB triggers a minor alteration in the OR transcriptome across AD stages, being necessary further developments that enable the analysis of OR family at protein level in the context of $\mathrm{AD}[11,39,40]$. Moreover, a slight deregulation of a subset of functional categories was observed in specific AD stages. As shown in Figure 4C, degradation of extracellular matrix, signaling by PDGF, and DAP12 were specifically mapped in initial stages. In line with our observations, gene modules regulated by PDGF, and DAP12 (or TYROBP) are disrupted in cortical structures from AD subjects [16]. Specifically, TYROBP expression is restricted to cells involved in the innate immunity [41], and is one of the causal regulator of the activated immune system network in late-onset AD [16]. On the other hand, metabolism of lipids, and aminoacids together with TCR signaling by ZAP-70 were exclusively detected in intermediate stages (Figure 4C). In advanced stages, gene clusters related to transcription, HSF1 activation, and ER to Golgi transport were specifically deregulated (Figure 4C).
A

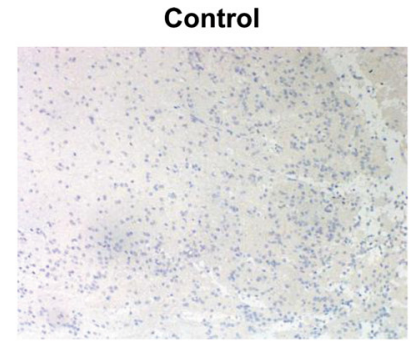

Intermediate AD

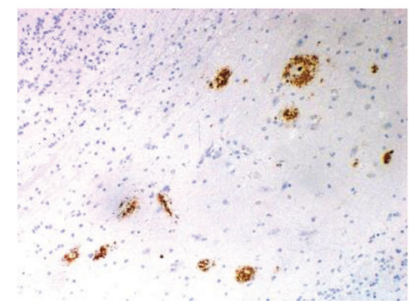

B

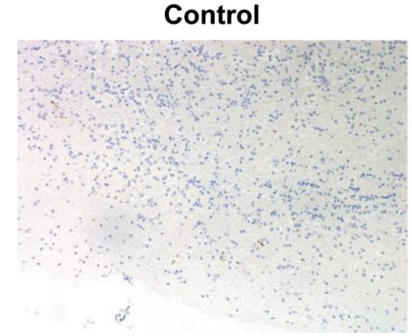

Intermediate AD

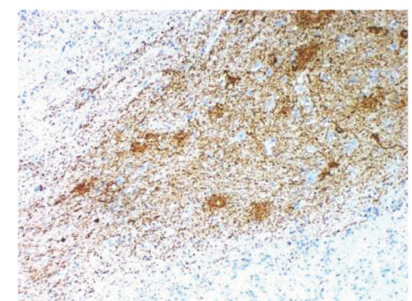

Low AD

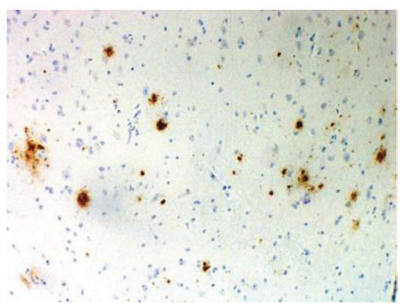

High AD

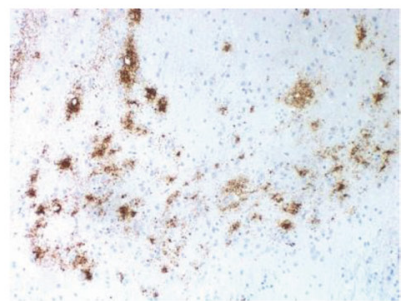

Low AD

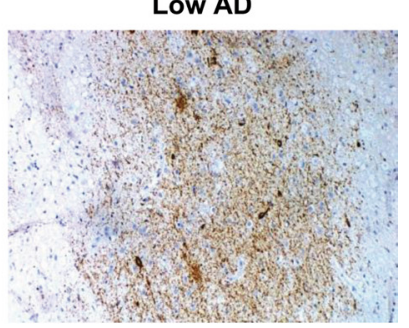

High AD

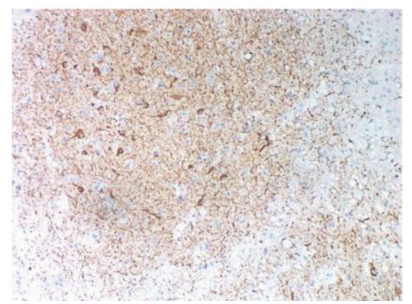

Figure 2: Representative immunohistochemical analysis of $\beta$-amyloid and phospho-Tau in the OB across AD stages. (A) Control: negative staining of $\beta$-amyloid in the anterior olfactory nucleus (AON). Low AD: mild compact deposits of $\beta$-amyloid in the AON. Intermediate AD: sparse neuritic plaques of $\beta$-amyloid in the AON. High AD: mild neuritic and diffuse plaques of $\beta$-amyloid in the AON. (B) Control: isolated neuropil threads of phospho-Tau protein in the glomerular layer of the OB. Initial AD: Moderate neuropil threads and tangles of phospho-Tau protein. Intermediate AD: Severe deposit of neuropil threads of phospho-Tau protein. Advanced AD: Severe neuropil threads and tangles of phospho-Tau protein in the AON (All images are $20 \times$ ). 


\section{Modulation of gene interactome networks in the $O B$ across AD stages}

To explore the cooperative action among differentially expressed genes, we performed gene-scale interaction networks merging the olfactory genes that tend to be de-regulated across AD staging. Using IPA software, a gene interactome map has been constructed for each $\mathrm{AD}$ stage (Figures 5-7). In this case, the integrative networkbased approach allowed us to: i) elucidate the biological function and molecular context of the deregulated genes in each neuropathological stage, ii) establish a framework to map interaction between deregulated genes and network modules across AD grading, and iii) to define potential causal regulators of the stage-dependent networks that may be considered as gene targets to modulate the disease progression at olfactory level. In initial AD stages, the top deregulated pathways proposed by IPA were estrogen biosynthesis ( $p$-value: 7,12E-03), cAMP-mediated signaling ( $p$-value: $1,02 \mathrm{E}-02)$, and Gi Signaling ( $p$-value: $1,15 \mathrm{E}-02$ ), suggesting a central function of EGFR in the functional network (Figure 5). In intermediate stages, communication between innate and adaptive immune cells ( $p$-value. 1,59E-03), and antigen presentation pathway
( $p$-value: 5,02E-03) were the top deregulated pathways, being TGF-beta, and CREB1 potential nodes of the network (Figure 6). In advanced stages, the functional module composed by STAT3, c-Jun, and APP nodes appears as one of the main axis in the network (Figure 7).

\section{Protein expression of predictive interactome hubs across AD grading: Focus on olfactory EGFR, CREB1, TGF-beta, c-Jun and STAT3}

Even though changes in their expression were not detected in our transcriptomic workflow, the alteration of some of their targets may be compatible with a dysregulation of their functionality during $\mathrm{AD}$ progression at the level of OB. For that, subsequent experiments were performed in order to monitor the OB protein expression of these signal transducers across AD stages. Although a deficient EGFR signaling affects the OBs in mice, being necessary for olfactory learning, and discrimination [42-44], an increment in olfactory EGFR protein expression was significantly detected in initial and advanced $\mathrm{AD}$ stages (Figure 8). Interestingly, intense EGFR expression has been also observed in hippocampal and cortical neuritic plaques from patients with
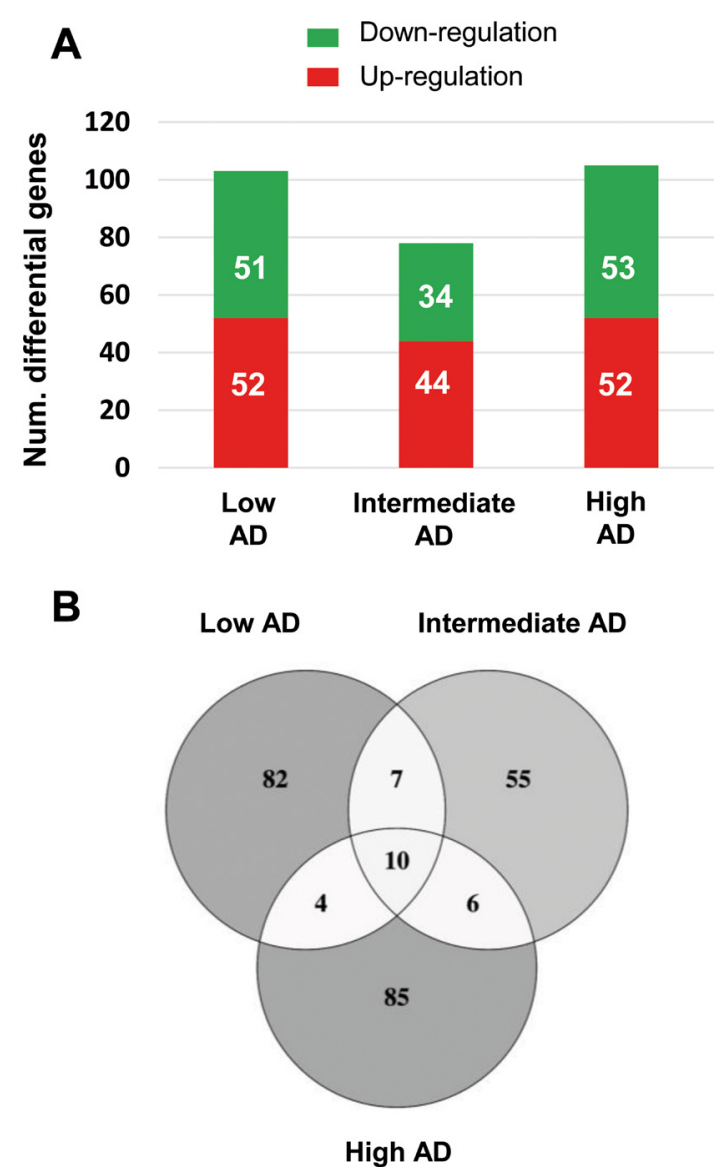

Figure 3: Differentially expressed genes in the $\mathrm{OB}$ across AD-related phenotypes. (A) Differential olfactory transcriptome distribution across AD stages. (B) Venn diagram of common and unique differential genes between AD stages. The distribution of common and distinct protein-coding genes in low, intermediate, and high AD stages is shown. 
pathologically confirmed $\mathrm{AD}$ [45], suggesting that abnormal EGFR signaling could contribute to cognitive impairment in AD [46]. CREB1 is at a central converging point of activated pathways during the processes of synaptic strengthening and memory formation, and targeted therapeutic strategies focusing on augmentation of CREB-mediated transcription might prove beneficial for the enhancement of both processes in initial stages of AD [47-49]. Disruption of these mechanisms in AD results in a reduction of CREB1 activation with accompanying memory impairment $[50,51]$. At olfactory level, most of the well-known activity-dependent CREB target genes such as $C$-FOS, FOSB, BDNF, NR4A2, and EGRl [50] were unchanged across AD stages (with the exception of CYR61 that was up-regulated in advanced stages)
(Supplementary Table 2). This transcriptomic fingerprint might partially corroborate the unmodified activation state of phosphorylated CREB (Ser133) observed at olfactory level during AD progression (Supplementary Figure 2). In relation to the predictive findings observed in Figure 7, it has been proposed that activated STAT3 is involved in the responsiveness of microglia to beta amyloid [52], being a common inducer of astrocyte reactivity in AD [53]. Moreover, STAT3 has been recently proposed as an upstream regulator in late onset $\mathrm{AD}$ at cortical level [27]. Accordingly, we observed an increment in the phosphorylation state of STAT3 (Y705) in advanced AD stages (Figure 8). In accordance with previous studies, the late STAT3 activation observed in the OB suggests an impairment in the differentiation process of olfactory

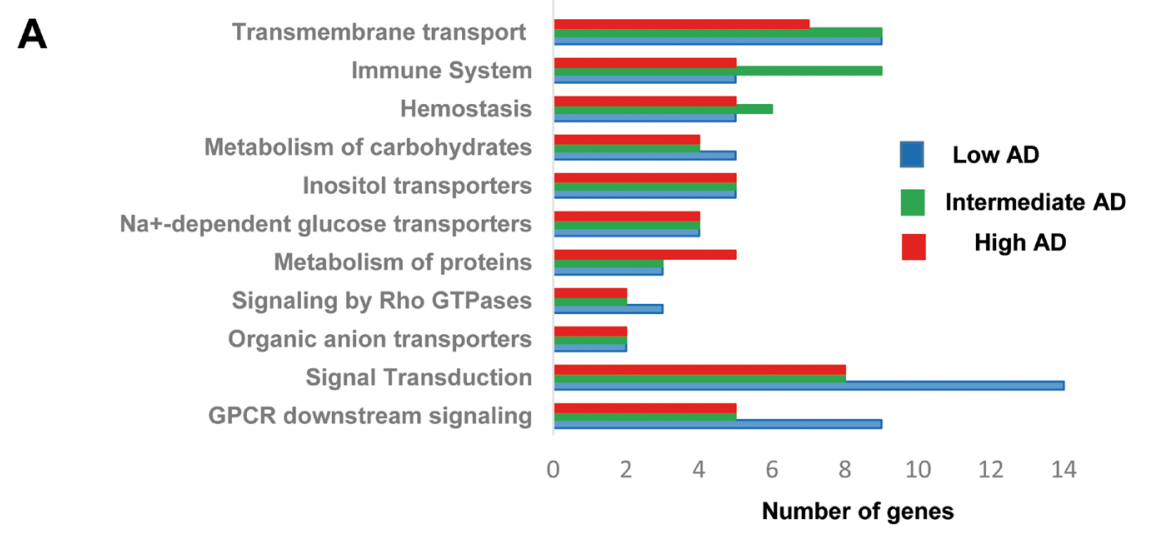

B
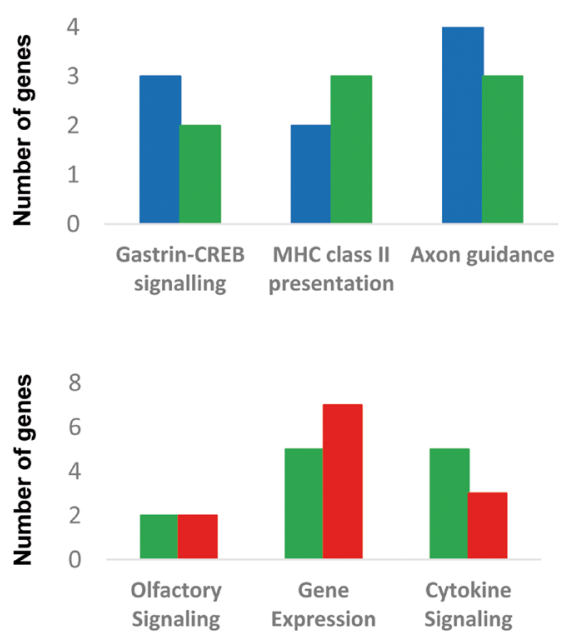

C

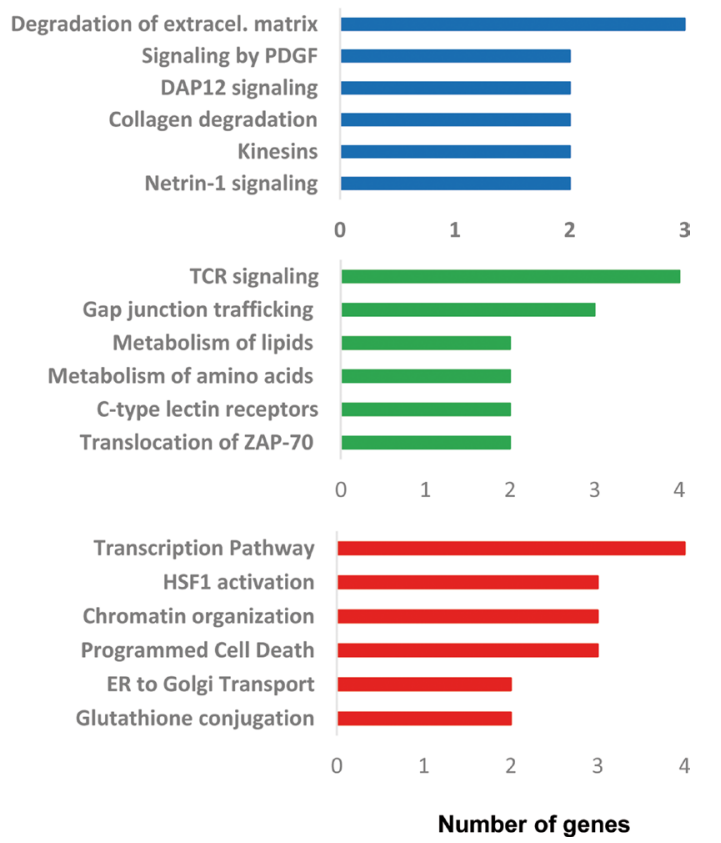

Figure 4: Functional metrics of the differential OB transcriptome across AD staging. Specific pathway analysis for the differential $\mathrm{OB}$ transcriptome detected in each $\mathrm{AD}$ stage is shown. Blue, green, and red bars correspond to functional deregulated categories in low, intermediate, and high AD stages respectively. 
neurons in advanced stages of the disease [54]. On the other hand, other hubs proposed by the interaction network analysis such as TGF-beta and c-Jun presented unmodified protein levels across AD grading (Supplementary Figure 2).

\section{Protein expression of olfactory EGFR, CREB1, TGF-beta, c-Jun and STAT3 across Alzheimer- related co-pathologies}

In contrast to the common separate investigation of neurological diseases, targeted cross-disease studies comparing shared molecular relationships may give new insights into possible olfactory perturbations common for all or some neurological disorders. In order to detect novel molecular features shared by different Alzheimer-related co-pathologies at olfactory level, we have evaluated the OB protein expression of EGFR, CREB1, TGF-beta, c-Jun, and STAT3 across several AD-related diseases $(n=28 \mathrm{OB}$ samples). We have included pathologies with common smell impairment like FTLD $[55,56]$, PSP where olfactory loss occurs to a lesser extent or is absent $[2,57,58]$, and mixed dementia. Mixed dementia is a condition in which $\mathrm{AD}$ and vascular dementia occur at the same time, and both separate disorders often display olfactory dysfunction $[59,60]$. As shown in Figure 9, EGFR protein levels were also increased in the $\mathrm{OB}$ derived from mixed dementia subjects (Figure 9A). As previously observed in AD, OB TGF-beta levels were unchanged across PSP, FTLD, and mixed dementia (Figure 9B). In contrast, OB protein levels of STAT3 and CREB1 were significantly increased only in mixed dementia, without apparent shifts in their activation status (Figure 9D and 9E). Differently from AD, olfactory c-Jun protein levels were exclusively increased in mixed dementia (Figure 9C). c-Jun up-regulation has also been reported in entorhinal cortex and hippocampus from AD subjects and also in AD transgenic mice [61-63]. Mechanistically, the c-Jun N terminal kinase (JNK)/c-Jun cascade exerts its influence in aberrant processes of AD

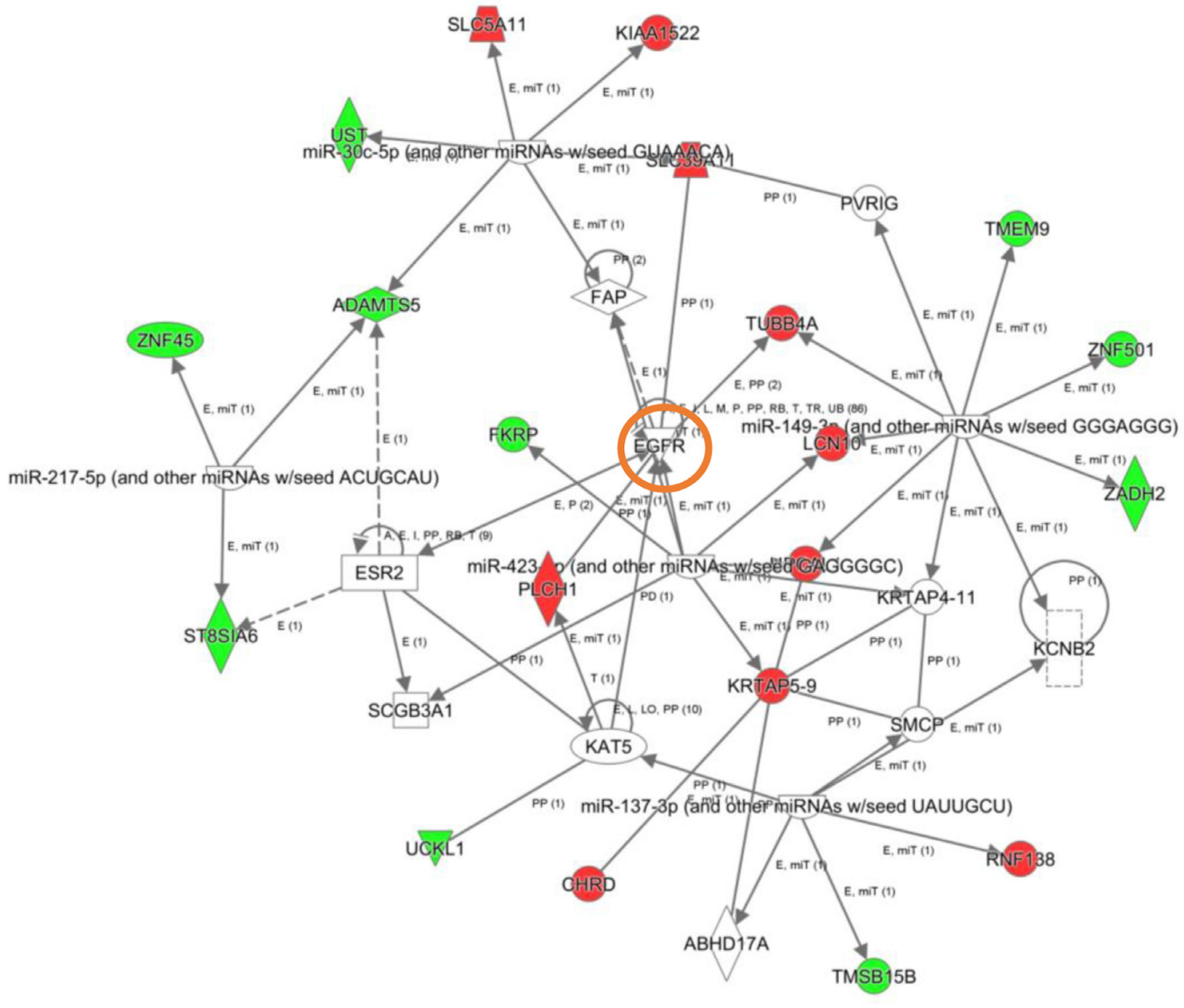

Figure 5: High-scoring gene interactome map for early differentially expressed genes in the OB during AD progression. Visual representation of the relationships between differential expressed genes and functional interactors in low AD stage. Dysregulated genes are highlighted in red (up-regulated) and green (down-regulated). Continuous and discontinuous lines represent direct and indirect interactions respectively. The complete legend including main features, molecule shapes, and relationships is found at http://ingenuity. force.com/ipa/articles/Feature_Description/Legend. 


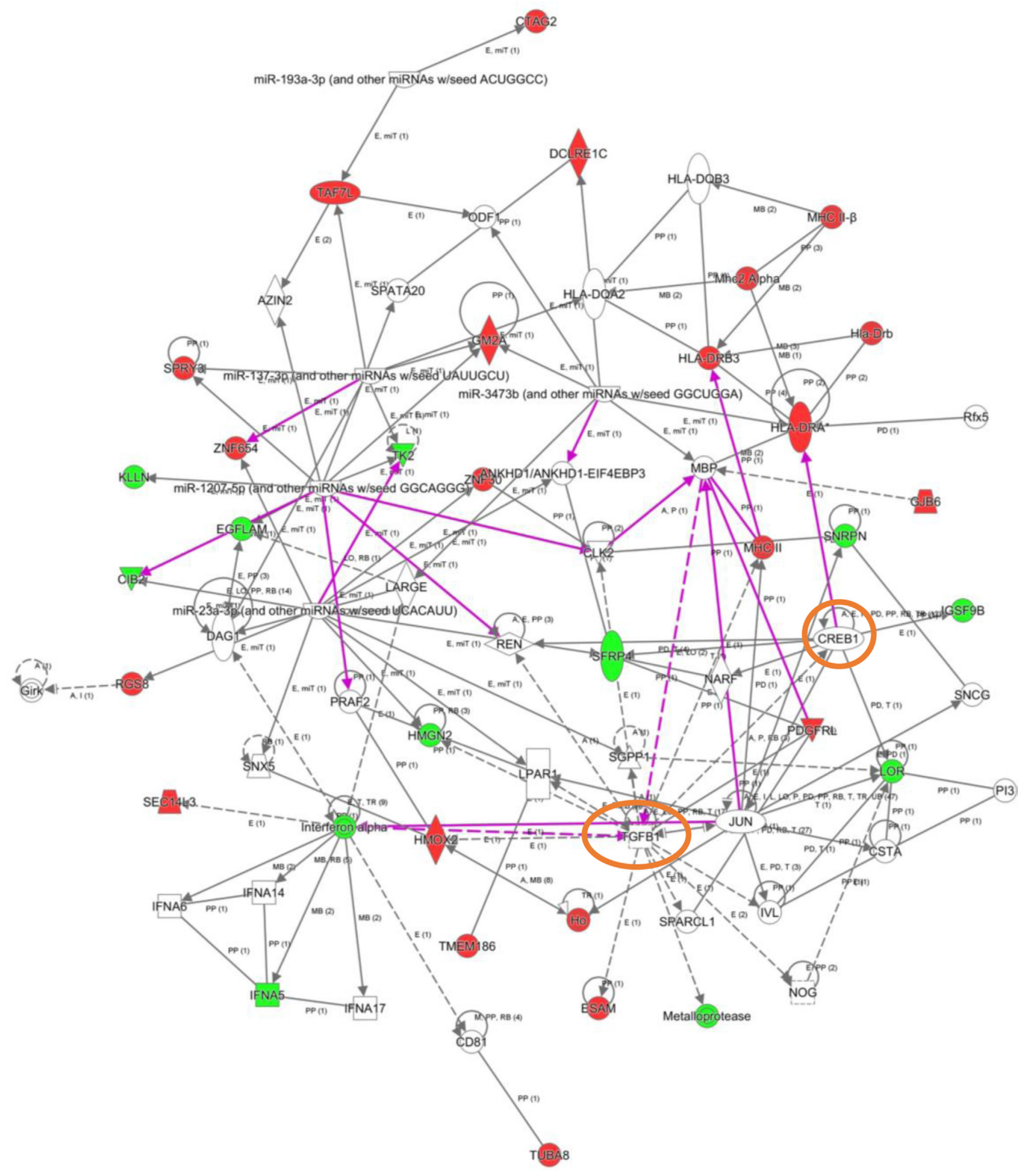

Figure 6: High-scoring gene interactome map for OB differentially expressed genes in intermediate AD stages. Visual representation of the relationships between differential expressed genes and functional interactors in intermediate stages. In this case, two networks were merged to facilitate the global interpretation (purple lines correspond to novel functional links after merging). Dysregulated genes are highlighted in red (up-regulated) and green (down-regulated). Continuous and discontinuous lines represent direct and indirect interactions respectively. The complete legend including main features, molecule shapes, and relationships may be found at http://ingenuity. force.com/ipa/articles/Feature_Description/Legend. 
pathogenesis such as Tau hyperphosphorylation, amyloid aggregation, and synaptic dysfunction in murine models of AD [64-66]. According to previous studies [67, 68], the c-Jun overexpression observed in the $\mathrm{OB}$ of mixed dementia subjects could contribute to some AD-related neuropathologies present in vascular dementia such as beta amyloid-induced neuroinflammation and vascular insufficiencies.

\section{MATERIALS AND METHODS}

\section{Materials}

The following antibodies and materials were used: anti-GAPDH (Calbiochem), anti-EGFR (Millipore), antiCREB, anti-phospho CREB (S133), anti-STAT3, antiphospho STAT3 (Y705), anti-c-Jun (Cell signaling), and
anti-TGF-beta (Abcam). Electrophoresis reagents were purchased from Biorad.

\section{Human samples}

According to the Spanish Law 14/2007 of Biomedical Research, inform written consent form of the Neurological Tissue Bank of Navarra Health Service was obtained for research purposes from relatives of patients included in this study. The study was conducted in accordance with the Declaration of Helsinki and all assessments, post-mortem evaluations, and procedures were previously approved by the Clinical Ethics Committee of Navarra Health Service. Fourteen AD cases were distributed into different groups according to specific consensus diagnostic criteria [69-71]: low, intermediate, and high AD neuropathological changes

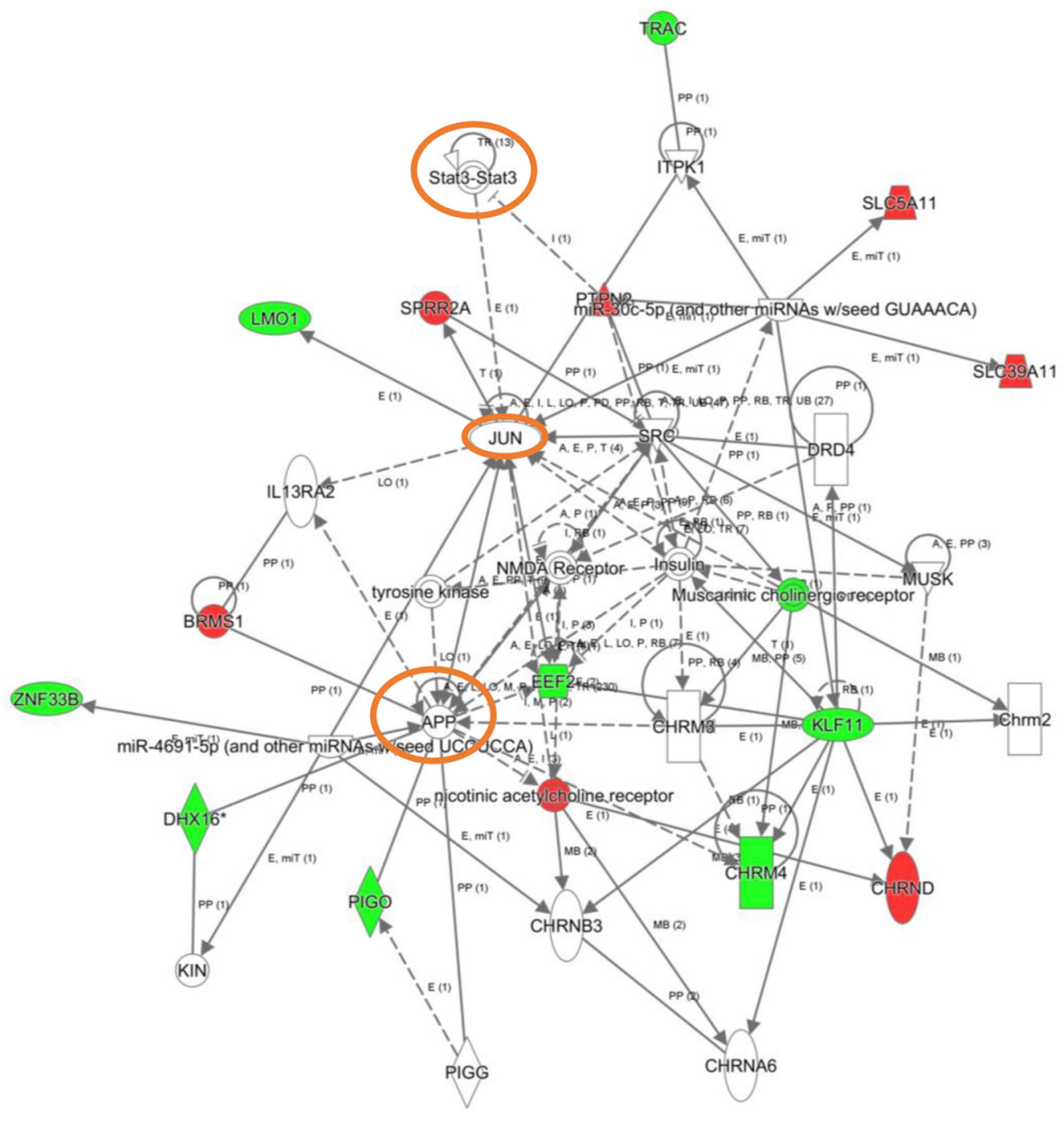

Figure 7: High-scoring gene interactome map for $\mathrm{OB}$ differentially expressed genes in high AD stages. Visual representation of the relationships between differential expressed genes and functional interactors is shown. Dysregulated genes are highlighted in red (up-regulated) and green (down-regulated). Continuous and discontinuous lines represent direct and indirect interactions respectively. The complete legend including main features, molecule shapes, and relationships may be found at http://ingenuity.force.com/ipa/articles/ Feature_Description/Legend. 
( $n=4-5$ /group). Four cases from elderly subjects with no history or histological findings of any neurological disease were used as a control group. All human brains considered in this study had a post-mortem interval (PMI) lower than 10 hours (Table 1). Brain processing and the neuropathological study for protein deposits aggregates beta-amyloid and phospho-Tau were performed as previously described [34]. For the discovery phase, neuropathological assessment was performed according to standardized neuropathological scoring/grading systems, including Thal phases of beta-amyloid deposition, Braak staging of neuro fibrillary lesions, Consortium to Established a Registry for Alzheimer's Disease, National Institute on Aging-Alzheimer's Association (NIA-AA) guidelines, and primary age-related tauopathy (PART) criteria [69-73]. For the cross-disease analysis, different clinical backgrounds were considered: Progressive supranuclear palsy (PSP) $(n=9$ cases; $4 \mathrm{~F} / 5 \mathrm{M}$; median age: 74 years), frontotemporal lobar degeneration (FTLD) ( $n=6 ; 3 \mathrm{~F} / 3 \mathrm{M}$; median age: 81 years), mixed dementia ( $\operatorname{mix} \mathrm{AD}$ VD) $(n=9$ cases; $4 \mathrm{~F} / 5 \mathrm{M}$; median age: 85 years), and additional controls $(n=4 ; 1 \mathrm{~F} / 3 \mathrm{M}$; median age: 80 years). In these cases, neuropathological assessment was performed according to standardized neuropathological guidelines: Mackenzie criteria for FTLD pathology [74], NINDS-AIREN criteria for vascular dementia [75], and NINDS criteria for PSP [76]. 80\% of the OB samples included in the cross-disease phase had a PMI lower than 10 hours (Supplementary Table 1).

\section{Microarray hybridization and data analysis}

For OB mRNA extraction, the Maxwell ${ }^{\circledR} 16$ simplyRNA Kit (Promega) was used. The sense cDNA was prepared from $1 \mathrm{ng}$ of total RNA and then fragmented and biotinylated using Affymetrix GeneChip ${ }^{\circledR}$ WT Pico Kit (PN902623). Labeled sense cDNA was hybridized to the Affymetrix Human Gene 2.0 ST chip according to the manufacturer protocols and using GeneChip ${ }^{\circledR}$ Hybridization, Wash and Stain Kit. Genechips were scanned with the Affymetrix GeneChip ${ }^{\circledR}$ Scanner 3000. For microarray data analysis, both background correction
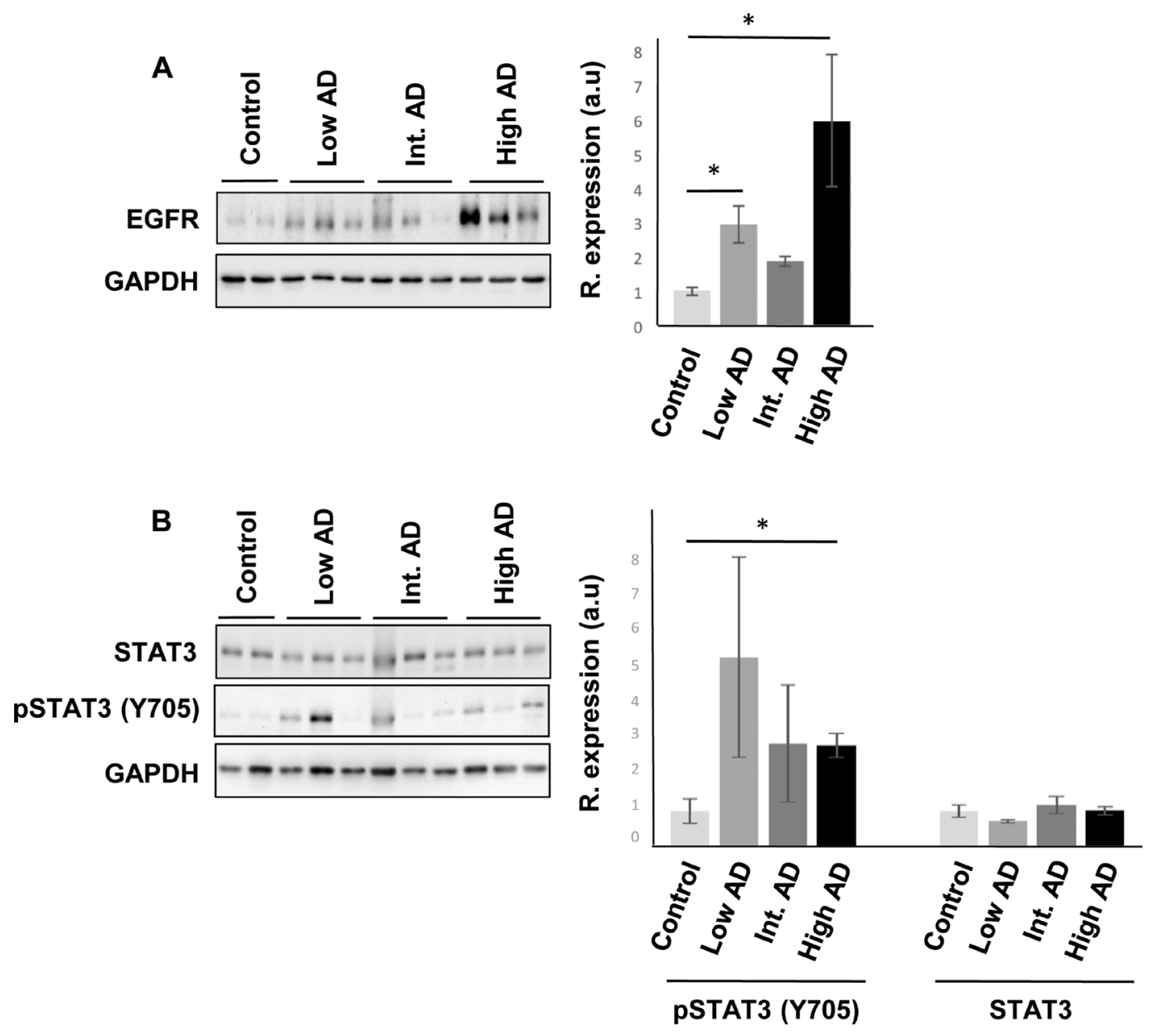

Figure 8: Olfactory bulb protein expression of EGFR, and STAT3 across AD staging. (A) Representative Western blot gels to detect olfactory EGFR across AD grading. (B) Protein expression of Total STAT3, and active STAT3 (Y705) in the OB during AD progression. Right panels shows histograms of band densities. Data are presented as mean \pm SEM from 3 independent OB samples per group. ${ }^{*} P<0.05$ vs control group. 
and normalization were done using RMA (Robust Multichip Average) algorithm [77]. Then, a filtering process was performed to eliminate low expression probe sets. Applying the criterion of an expression value of 16 in at least 2 samples for each experimental condition, 28353 probe sets were selected. R/Bioconductor was used for preprocessing and statistical analysis. For analysis of genes related to pathological changes, individuals with AD pathology were compared to non-demented controls. LIMMA (Linear Models for Microarray Data) was used to find out the probe sets that showed significant differential expression between controls and AD stages. We first used a threshold criteria of False Discovery Rate (FDR) < $5 \%$ to select differentially expressed genes. As in other transcriptomic studies performed in $\mathrm{AD}$ brains $[15,78]$, we did not achieve significant results using this criteria, so we worked with a $p$-value $<0.01$ (without using any method for multiple testing correction). Microarray data files were submitted to the GEO (Gene Expression Omnibus) database and are available under accession number GSE93885.

The differential expression of RNAs was functionally analyzed through the use of Reactome [33], and QIAGEN's Ingenuity ${ }^{\circledR}$ Pathway Analysis (IPA) (QIAGEN Redwood City, www.qiagen.com/ingenuity), in order to detect and infer differentially activated/ deactivated pathways as a result of AD phenotypes. IPA software comprises curated information from databases of
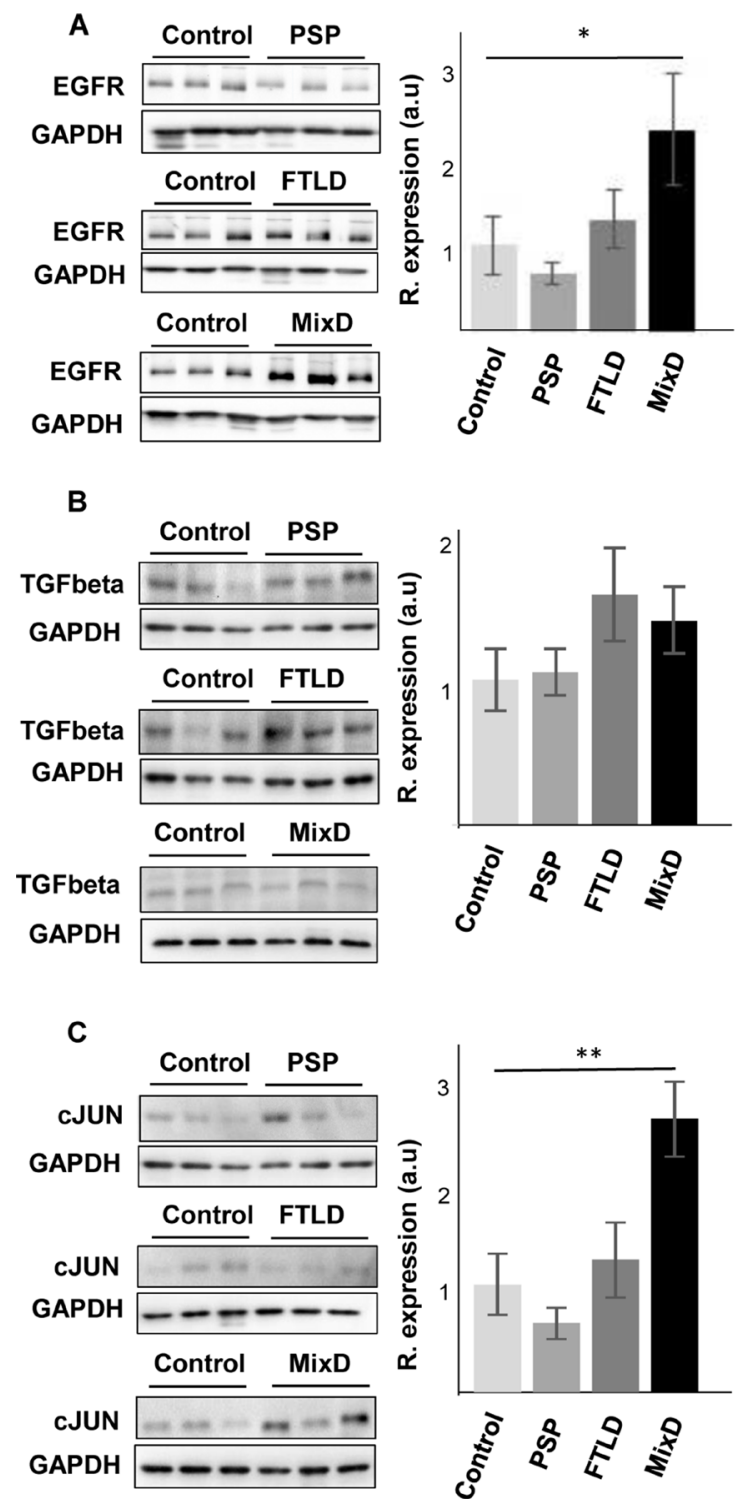
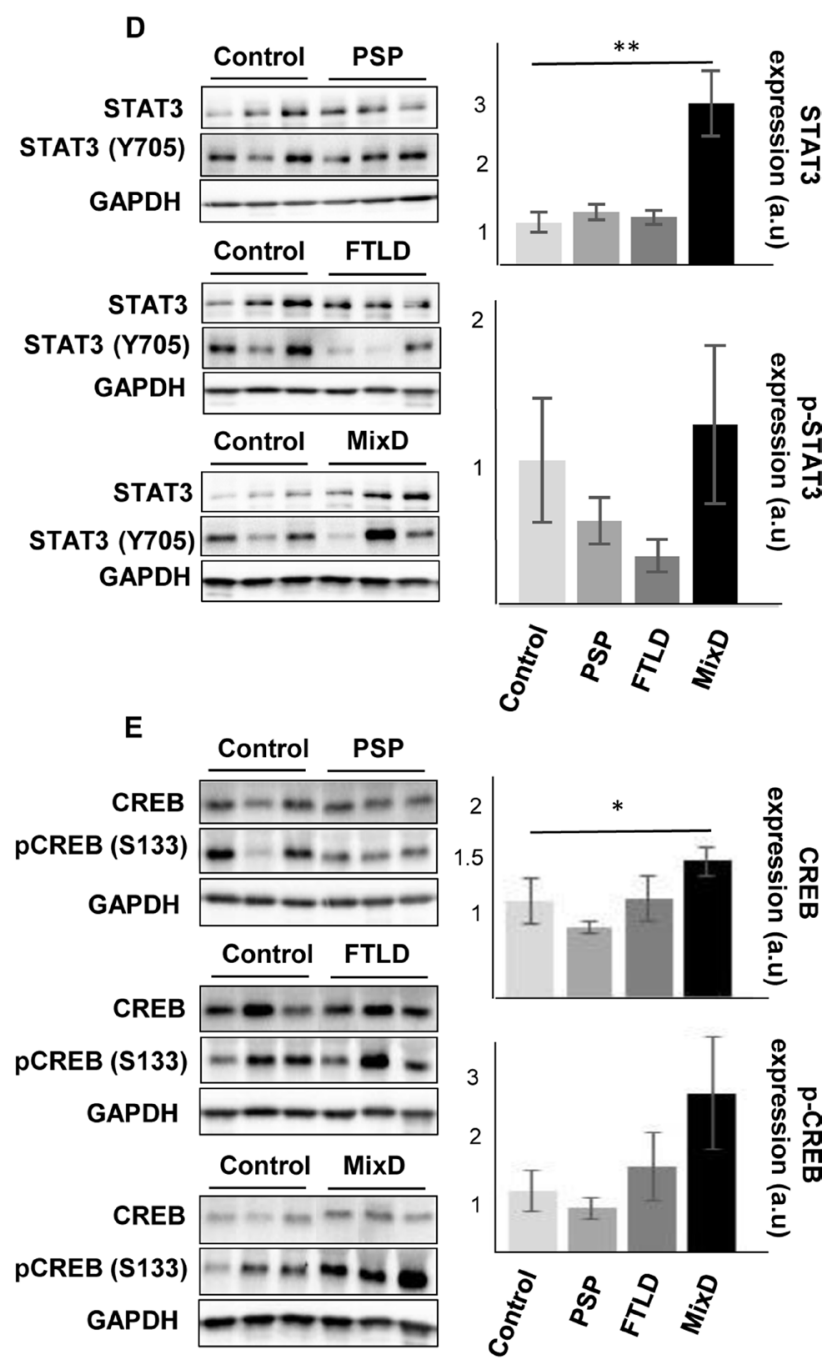

Figure 9: Olfactory bulb protein expression of EGFR, CREB1, TGF-beta, c-Jun and STAT3 across proteinopathies. OB Protein expression was documented by Western blot. (A) EGFR expression, (B) TGF-beta expression, (C) c-Jun expression, (D) STAT3/ phospho-STAT3 (Y705) expression, and (E) CREB/phospho-CREB (S133) expression, in PSP, FTLD, and mixed dementia subjects. Graphs represent histograms of band densities. Data are presented as mean \pm SEM from: Controls $(n=4$ cases), PSP $(n=9$ cases), FTLD ( $n=6$ cases), and mixed dementia (mix AD VD) ( $n=9$ cases). $* P<0.05$ vs control group; $* * P<0.01$ vs control group. 
experimental and predictive origin, enabling discovery of highly represented functions, pathways, and interactome networks.

\section{Western blotting}

Equal amounts of protein $(10 \mu \mathrm{g})$ were resolved in $12.5 \%$ SDS-PAGE gels. OB proteins derived from human samples were electrophoretically transferred onto nitrocellulose membranes for $45 \mathrm{~min}$ at $120 \mathrm{~V}$. Equal loading of the gels was assessed by Ponceau staining. Membranes were probed with primary antibodies at 1:1000 dilution in 5\% nonfat milk or BSA. After incubation with the appropriate horseradish peroxidase-conjugated secondary antibody (1:5000), antibody binding was detected by a ChemidocäMP Imaging System (Bio-Rad) after incubation with an enhanced chemiluminescence substrate (Perkin Elmer). All Band intensities were measured with Image Lab Software Version 5.2 (Bio-Rad) and normalized to GAPDH.

\section{CONCLUSIONS}

Summing up, we have performed a stage-dependent comprehensive analysis of differential expression of $\mathrm{OB}$ coding transcripts during $\mathrm{AD}$ progression. To the best of our knowledge, this is the first study to characterize in depth, potential $\mathrm{AD}$-associated transcriptional changes in the human $\mathrm{OB}$. We performed gene set enrichment analysis to find the most relevant pathways and gene regulatory networks that are progressively modulated during $\mathrm{AD}$ progression. More importantly, using a discovery platform combining neuropathological diagnosis, OB transcriptome exploration, functional interaction data, together with a cross-disease analysis, a divergent olfactory expression of specific signal transducers has been observed across ADrelated co-pathologies, serving as a foundation for new research areas into the role of olfactory signaling across different types of dementias.

\section{Abbreviations}

AD: Alzheimer's disease; CREB1: cAMP Responsive Element Binding Protein 1; c-Jun: AP-1 Transcription Factor Subunit; EGFR: Epidermal growth factor receptor; FTLD: Frontotemporal lobar degeneration; OB: olfactory bulb; PSP: Progressive supranuclear palsy; STAT3: Signal transducer and activator of transcription 3; TGF-beta: Transforming growth factor beta.

\section{Authors' contributions}

Conceptualization: ES; Data curation: VS, ES; Formal analysis: ML, JFI, ES; Investigation: ML, MVZ, JFI, ES; Methodology: ML, MVZ, JFI, ES; Project administration:
ES; Software: ML, VS; Supervision: JFI, ES; Funding acquisition: JFI, ES. All authors contributed to the general discussion and comment on the manuscript. ES wrote the manuscript with inputs from ML, MVZ, VS, and JFI.

\section{ACKNOWLEDGMENTS}

We are very grateful to the patients and relatives that generously donor the brain tissue for research purposes. The authors thank the Neurological Tissue Bank of Navarra Health Service for providing us the OB specimens and Lourdes Ortíz from the Genomics Core Facility from CIMA (Pamplona, Spain) for sharing experiences on brain transcriptomics. The technical assistance of Estela PérezValderrama and Karina Ausín is greatly acknowledged.

\section{CONFLICTS OF INTEREST}

$$
\text { No potential conflicts of interest to disclose }
$$

\section{FUNDING}

This work was funded by grants from the Spanish Ministry of Economy and Competitiveness (MINECO) (Ref. SAF2014-59340-R), Department of Economic Development from Government of Navarra (Ref. PC025), and Obra Social la Caixa to ES. MLM is supported by a predoctoral fellowship from the Public University of Navarra. The Proteomics Unit of Navarrabiomed is a member of Proteored, PRB2-ISCIII, and is supported by grant PT13/0001, of the PE I+D+I 2013-2016 funded by ISCIII and FEDER.

\section{REFERENCES}

1. Bahar-Fuchs A, Chetelat G, Villemagne VL, Moss S, Pike K, Masters CL, Rowe C, Savage G. Olfactory deficits and amyloid-beta burden in Alzheimer's disease, mild cognitive impairment, and healthy aging: a PiB PET study. J Alzheimers Dis. 2010; 22:1081-1087.

2. Attems J, Walker L, Jellinger KA. Olfactory bulb involvement in neurodegenerative diseases. Acta Neuropathol. 2014; 127:459-475.

3. Doty RL. The olfactory vector hypothesis of neurodegenerative disease: is it viable? Ann Neurol. 2008; 63:7-15.

4. Thomann PA, Dos Santos V, Seidl U, Toro P, Essig M, Schroder J. MRI-derived atrophy of the olfactory bulb and tract in mild cognitive impairment and Alzheimer's disease. J Alzheimers Dis. 2009; 17:213-221.

5. Forster S, Vaitl A, Teipel SJ, Yakushev I, Mustafa M, la Fougere C, Rominger A, Cumming P, Bartenstein P, Hampel H, Hummel T, Buerger K, Hundt $\mathrm{W}$, et al. Functional representation of olfactory impairment in early Alzheimer's disease. J Alzheimers Dis. 2010; 22:581-591. 
6. Kovacs T, Cairns NJ, Lantos PL. Olfactory centres in Alzheimer's disease: olfactory bulb is involved in early Braak's stages. Neuroreport. 2001; 12:285-288.

7. Attems J, Jellinger KA. Olfactory tau pathology in Alzheimer disease and mild cognitive impairment. Clin Neuropathol. 2006; 25:265-271.

8. Arnold SE, Lee EB, Moberg PJ, Stutzbach L, Kazi H, Han LY, Lee VM, Trojanowski JQ. Olfactory epithelium amyloid-beta and paired helical filament-tau pathology in Alzheimer disease. Ann Neurol. 2010; 67:462-469.

9. Talamo BR, Rudel R, Kosik KS, Lee VM, Neff S, Adelman L, Kauer JS. Pathological changes in olfactory neurons in patients with Alzheimer's disease. Nature. 1989; 337:736-739.

10. Lotsch J, Schaeffeler E, Mittelbronn M, Winter S, Gudziol V, Schwarzacher SW, Hummel T, Doehring A, Schwab M, Ultsch A. Functional genomics suggest neurogenesis in the adult human olfactory bulb. Brain Struct Funct. 2014.

11. Lachen-Montes M, Fernandez-Irigoyen J, Santamaria E. Deconstructing the molecular architecture of olfactory areas using proteomics. Proteomics Clin Appl. 2016; 10:1178-1190.

12. Cooper-Knock J, Kirby J, Ferraiuolo L, Heath PR, Rattray M, Shaw PJ. Gene expression profiling in human neurodegenerative disease. Nat Rev Neurol. 2012; 8:518-530.

13. Katsel $\mathrm{P}, \mathrm{Li} \mathrm{C}$, Haroutunian V. Gene expression alterations in the sphingolipid metabolism pathways during progression of dementia and Alzheimer's disease: a shift toward ceramide accumulation at the earliest recognizable stages of Alzheimer's disease? Neurochem Res. 2007; 32:845-856.

14. Katsel P, Tan W, Haroutunian V. Gain in brain immunity in the oldest-old differentiates cognitively normal from demented individuals. PLoS One. 2009; 4:e7642.

15. Silva AR, Grinberg LT, Farfel JM, Diniz BS, Lima LA, Silva PJ, Ferretti RE, Rocha RM, Filho WJ, Carraro DM, Brentani H. Transcriptional alterations related to neuropathology and clinical manifestation of Alzheimer's disease. PLoS One. 2012; 7:e48751.

16. Zhang B, Gaiteri C, Bodea LG, Wang Z, McElwee J, Podtelezhnikov AA, Zhang C, Xie T, Tran L, Dobrin R, Fluder E, Clurman B, Melquist S, et al. Integrated systems approach identifies genetic nodes and networks in late-onset Alzheimer's disease. Cell. 2013; 153:707-720.

17. Rey NL, Wesson DW, Brundin P. The olfactory bulb as the entry site for prion-like propagation in neurodegenerative diseases. Neurobiol Dis. 2016.

18. Roberts RO, Christianson TJ, Kremers WK, Mielke MM, Machulda MM, Vassilaki M, Alhurani RE, Geda YE, Knopman DS, Petersen RC. Association Between Olfactory Dysfunction and Amnestic Mild Cognitive Impairment and Alzheimer Disease Dementia. JAMA Neurol. 2016; 73:93-101.

19. Zhu YY, Ni DF, Xu CM. Gene expression profiles in the olfactory bulb from a rat model of Alzheimer's disease. J Alzheimers Dis. 2009; 18:581-593.
20. Masurkar AV, Devanand DP. Olfactory Dysfunction in the Elderly: Basic Circuitry and Alterations with Normal Aging and Alzheimer's Disease. Curr Geriatr Rep. 2014; 3:91-100.

21. Leite RE, Grinberg LT. Closing the gap between brain banks and proteomics to advance the study of neurodegenerative diseases. Proteomics Clin Appl. 2015.

22. Xu PT, Li YJ, Qin XJ, Scherzer CR, Xu H, Schmechel DE, Hulette CM, Ervin J, Gullans SR, Haines J, PericakVance MA, Gilbert JR. Differences in apolipoprotein E3/3 and E4/4 allele-specific gene expression in hippocampus in Alzheimer disease. Neurobiol Dis. 2006; 21:256-275.

23. Liang WS, Dunckley T, Beach TG, Grover A, Mastroeni D, Ramsey K, Caselli RJ, Kukull WA, McKeel D, Morris JC, Hulette CM, Schmechel D, Reiman EM, et al. Altered neuronal gene expression in brain regions differentially affected by Alzheimer's disease: a reference data set. Physiol Genomics. 2008; 33:240-256.

24. Parachikova A, Agadjanyan MG, Cribbs DH, BlurtonJones M, Perreau V, Rogers J, Beach TG, Cotman CW. Inflammatory changes parallel the early stages of Alzheimer disease. Neurobiol Aging. 2007; 28:1821-1833.

25. Bossers K, Wirz KT, Meerhoff GF, Essing AH, van Dongen JW, Houba P, Kruse CG, Verhaagen J, Swaab DF. Concerted changes in transcripts in the prefrontal cortex precede neuropathology in Alzheimer's disease. Brain. 2010; 133:3699-3723.

26. Tan MG, Chua WT, Esiri MM, Smith AD, Vinters HV, Lai MK. Genome wide profiling of altered gene expression in the neocortex of Alzheimer's disease. J Neurosci Res. 2010; 88:1157-1169.

27. Li X, Long J, He T, Belshaw R, Scott J. Integrated genomic approaches identify major pathways and upstream regulators in late onset Alzheimer's disease. Sci Rep. 2015; 5:12393.

28. Kotlyar M, Pastrello C, Pivetta F, Lo Sardo A, Cumbaa C, Li H, Naranian T, Niu Y, Ding Z, Vafaee F, BroackesCarter F, Petschnigg J, Mills GB, et al. In silico prediction of physical protein interactions and characterization of interactome orphans. Nat Methods. 2015; 12:79-84.

29. Morihara T, Hayashi N, Yokokoji M, Akatsu H, Silverman MA, Kimura N, Sato M, Saito Y, Suzuki T, Yanagida K, Kodama TS, Tanaka T, Okochi M, et al. Transcriptome analysis of distinct mouse strains reveals kinesin light chain-1 splicing as an amyloid-beta accumulation modifier. Proc Natl Acad Sci USA. 2014; 111:2638-2643.

30. Hondius DC, van Nierop P, Li KW, Hoozemans JJ, van der Schors RC, van Haastert ES, van der Vies SM, Rozemuller AJ, Smit AB. Profiling the human hippocampal proteome at all pathologic stages of Alzheimer's disease. Alzheimers Dement. 2016; 12:654-668.

31. Nagayama S, Homma R, Imamura F. Neuronal organization of olfactory bulb circuits. Front Neural Circuits. 2014; 8:98. 
32. Lovatt D, Bell T, Eberwine J. Single-neuron isolation for RNA analysis using pipette capture and laser capture microdissection. Cold Spring Harb Protoc. 2015; 2015:pdb prot072439.

33. Fabregat A, Sidiropoulos K, Garapati P, Gillespie M, Hausmann K, Haw R, Jassal B, Jupe S, Korninger F, McKay S, Matthews L, May B, Milacic M, et al. The Reactome pathway Knowledgebase. Nucleic Acids Res. 2016; 44:D481-487.

34. Zelaya MV, Perez-Valderrama E, de Morentin XM, Tunon T, Ferrer I, Luquin MR, Fernandez-Irigoyen J, Santamaria E. Olfactory bulb proteome dynamics during the progression of sporadic Alzheimer's disease: identification of common and distinct olfactory targets across Alzheimerrelated co-pathologies. Oncotarget. 2015; 6:39437-39456. https://doi.org/10.18632/oncotarget.6254.

35. Walton NM, de Koning A, Xie X, Shin R, Chen Q, Miyake S, Tajinda K, Gross AK, Kogan JH, Heusner CL, Tamura K, Matsumoto M. Gastrin-releasing peptide contributes to the regulation of adult hippocampal neurogenesis and neuronal development. Stem Cells. 2014; 32:2454-2466.

36. Horgusluoglu E, Nudelman K, Nho K, Saykin AJ. Adult neurogenesis and neurodegenerative diseases: A systems biology perspective. Am J Med Genet B Neuropsychiatr Genet. 2016; 174:93-112.

37. Narayan PJ, Lill C, Faull R, Curtis MA, Dragunow M. Increased acetyl and total histone levels in post-mortem Alzheimer's disease brain. Neurobiol Dis. 2015; 74:281-294.

38. Ansoleaga B, Garcia-Esparcia P, Llorens F, Moreno J, Aso E, Ferrer I. Dysregulation of brain olfactory and taste receptors in $\mathrm{AD}$, PSP and CJD, and AD-related model. Neuroscience. 2013; 248:369-382.

39. Xu A, Li G, Yang D, Wu S, Ouyang H, Xu P, He F. Evolutionary Characteristics of Missing Proteins: Insights into the Evolution of Human Chromosomes Related to Missing-Protein-Encoding Genes. J Proteome Res. 2015; 14:4985-4994.

40. Choong WK, Chang HY, Chen CT, Tsai CF, Hsu WL, Chen YJ, Sung TY. Informatics View on the Challenges of Identifying Missing Proteins from Shotgun Proteomics. J Proteome Res. 2015; 14:5396-5407.

41. Schleinitz N, Chiche L, Guia S, Bouvier G, Vernier J, Morice A, Houssaint E, Harle JR, Kaplanski G, MonteroJulian FA, Vely F. Pattern of DAP12 expression in leukocytes from both healthy and systemic lupus erythematosus patients. PLoS One. 2009; 4:e6264.

42. Wagner B, Natarajan A, Grunaug S, Kroismayr R, Wagner EF, Sibilia M. Neuronal survival depends on EGFR signaling in cortical but not midbrain astrocytes. EMBO J. 2006; 25:752-762.

43. Rahn T, Leippe M, Roeder T, Fedders H. EGFR signaling in the brain is necessary for olfactory learning in Drosophila larvae. Learn Mem. 2013; 20:194-200.

44. Enwere E, Shingo T, Gregg C, Fujikawa H, Ohta S, Weiss S. Aging results in reduced epidermal growth factor receptor signaling, diminished olfactory neurogenesis, and deficits in fine olfactory discrimination. J Neurosci. 2004; 24:8354-8365.

45. Birecree E, Whetsell WO Jr, Stoscheck C, King LE Jr, Nanney LB. Immunoreactive epidermal growth factor receptors in neuritic plaques from patients with Alzheimer's disease. J Neuropathol Exp Neurol. 1988; 47:549-560.

46. Hochstrasser T, Ehrlich D, Marksteiner J, SpernerUnterweger B, Humpel C. Matrix metalloproteinase-2 and epidermal growth factor are decreased in platelets of Alzheimer patients. Curr Alzheimer Res. 2012; 9:982-989.

47. Sakamoto K, Karelina K, Obrietan K. CREB: a multifaceted regulator of neuronal plasticity and protection. J Neurochem. 2011; 116:1-9.

48. Tully T, Bourtchouladze R, Scott R, Tallman J. Targeting the CREB pathway for memory enhancers. Nat Rev Drug Discov. 2003; 2:267-277.

49. Teich AF, Nicholls RE, Puzzo D, Fiorito J, Purgatorio R, Fa M, Arancio O. Synaptic therapy in Alzheimer's disease: a CREB-centric approach. Neurotherapeutics. 2015; 12:29-41.

50. Saura CA. CREB-regulated transcription coactivator 1-dependent transcription in Alzheimer's disease mice. Neurodegener Dis. 2012; 10:250-252.

51. Saura CA, Valero J. The role of CREB signaling in Alzheimer's disease and other cognitive disorders. Rev Neurosci. 2011; 22:153-169.

52. Eufemi M, Cocchiola R, Romaniello D, Correani V, Di Francesco L, Fabrizi C, Maras B, Schinina ME. Acetylation and phosphorylation of STAT3 are involved in the responsiveness of microglia to beta amyloid. Neurochem Int. 2015; 81:48-56.

53. Ben Haim L, Ceyzeriat K, Carrillo-de Sauvage MA, Aubry F, Auregan G, Guillermier M, Ruiz M, Petit F, Houitte D, Faivre E, Vandesquille M, Aron-Badin R, Dhenain M, et al. The JAK/STAT3 pathway is a common inducer of astrocyte reactivity in Alzheimer's and Huntington's diseases. J Neurosci. 2015; 35:2817-2829.

54. Yu Y, Ren W, Ren B. Expression of signal transducers and activator of transcription 3 (STAT3) determines differentiation of olfactory bulb cells. Mol Cell Biochem. 2009; 320:101-108.

55. Luzzi S, Snowden JS, Neary D, Coccia M, Provinciali L, Lambon Ralph MA. Distinct patterns of olfactory impairment in Alzheimer's disease, semantic dementia, frontotemporal dementia, and corticobasal degeneration. Neuropsychologia. 2007; 45:1823-1831.

56. McLaughlin NC, Westervelt HJ. Odor identification deficits in frontotemporal dementia: a preliminary study. Arch Clin Neuropsychol. 2008; 23:119-123.

57. Doty RL. Olfactory dysfunction in Parkinson disease. Nat Rev Neurol. 2012; 8:329-339.

58. Hoyles K, Sharma JC. Olfactory loss as a supporting feature in the diagnosis of Parkinson's disease: a pragmatic approach. J Neurol. 2013; 260:2951-2958. 
59. Alves J, Petrosyan A, Magalhaes R. Olfactory dysfunction in dementia. World J Clin Cases. 2014; 2:661-667.

60. Gray AJ, Staples V, Murren K, Dhariwal A, Bentham P. Olfactory identification is impaired in clinic-based patients with vascular dementia and senile dementia of Alzheimer type. Int J Geriatr Psychiatry. 2001; 16:513-517.

61. Anderson $\mathrm{AJ}, \mathrm{Su} \mathrm{JH}$, Cotman $\mathrm{CW}$. DNA damage and apoptosis in Alzheimer's disease: colocalization with c-Jun immunoreactivity, relationship to brain area, and effect of postmortem delay. J Neurosci. 1996; 16:1710-1719.

62. Marcus DL, Strafaci JA, Miller DC, Masia S, Thomas CG, Rosman J, Hussain S, Freedman ML. Quantitative neuronal c-fos and c-jun expression in Alzheimer's disease. Neurobiol Aging. 1998; 19:393-400.

63. Thakur A, Wang X, Siedlak SL, Perry G, Smith MA, Zhu X. c-Jun phosphorylation in Alzheimer disease. J Neurosci Res. 2007; 85:1668-1673.

64. Savage MJ, Lin YG, Ciallella JR, Flood DG, Scott RW. Activation of c-Jun N-terminal kinase and p38 in an Alzheimer's disease model is associated with amyloid deposition. J Neurosci. 2002; 22:3376-3385.

65. Ploia C, Antoniou X, Sclip A, Grande V, Cardinetti D, Colombo A, Canu N, Benussi L, Ghidoni R, Forloni G, Borsello T. JNK plays a key role in tau hyperphosphorylation in Alzheimer's disease models. J Alzheimers Dis. 2011; 26:315-329.

66. Sclip A, Tozzi A, Abaza A, Cardinetti D, Colombo I, Calabresi P, Salmona M, Welker E, Borsello T. c-Jun $\mathrm{N}$-terminal kinase has a key role in Alzheimer disease synaptic dysfunction in vivo. Cell Death Dis. 2014; 5:e1019.

67. Bamji-Mirza M, Callaghan D, Najem D, Shen S, Hasim MS, Yang Z, Zhang W. Stimulation of insulin signaling and inhibition of JNK-AP1 activation protect cells from amyloidbeta-induced signaling dysregulation and inflammatory response. J Alzheimers Dis. 2014; 40:105-122.

68. Vukic V, Callaghan D, Walker D, Lue LF, Liu QY, Couraud PO, Romero IA, Weksler B, Stanimirovic DB, Zhang W. Expression of inflammatory genes induced by beta-amyloid peptides in human brain endothelial cells and in Alzheimer's brain is mediated by the JNK-AP1 signaling pathway. Neurobiol Dis. 2009; 34:95-106.

69. Braak H, Alafuzoff I, Arzberger T, Kretzschmar H, Del Tredici K. Staging of Alzheimer disease-associated neurofibrillary pathology using paraffin sections and immunocytochemistry. Acta Neuropathol. 2006; 112:389-404.

70. Alafuzoff I, Arzberger T, Al-Sarraj S, Bodi I, Bogdanovic N, Braak H, Bugiani O, Del-Tredici K, Ferrer I, Gelpi E,
Giaccone G, Graeber MB, Ince P, et al. Staging of neurofibrillary pathology in Alzheimer's disease: a study of the BrainNet Europe Consortium. Brain Pathol. 2008; 18:484-496.

71. Montine TJ, Phelps CH, Beach TG, Bigio EH, Cairns NJ, Dickson DW, Duyckaerts C, Frosch MP, Masliah E, Mirra SS, Nelson PT, Schneider JA, Thal DR, et al. National Institute on Aging-Alzheimer's Association guidelines for the neuropathologic assessment of Alzheimer's disease: a practical approach. Acta Neuropathol. 2012; 123:1-11.

72. Thal DR, Rub U, Orantes M, Braak H. Phases of A betadeposition in the human brain and its relevance for the development of AD. Neurology. 2002; 58:1791-1800.

73. Crary JF, Trojanowski JQ, Schneider JA, Abisambra JF, Abner EL, Alafuzoff I, Arnold SE, Attems J, Beach TG, Bigio EH, Cairns NJ, Dickson DW, Gearing M, et al. Primary age-related tauopathy (PART): a common pathology associated with human aging. Acta Neuropathol. $2014 ; 128: 755-766$.

74. Mackenzie IR, Neumann M, Baborie A, Sampathu DM, Du Plessis D, Jaros E, Perry RH, Trojanowski JQ, Mann DM, Lee VM. A harmonized classification system for FTLDTDP pathology. Acta Neuropathol. 2011; 122:111-113.

75. Roman GC, Tatemichi TK, Erkinjuntti T, Cummings JL, Masdeu JC, Garcia JH, Amaducci L, Orgogozo JM, Brun A, Hofman A, Moody DM, O'Brien MD, Yamaguchi T, et al. Vascular dementia: diagnostic criteria for research studies. Report of the NINDS-AIREN International Workshop. Neurology. 1993; 43:250-260.

76. Litvan I, Hauw JJ, Bartko JJ, Lantos PL, Daniel SE, Horoupian DS, McKee A, Dickson D, Bancher C, Tabaton M, Jellinger K, Anderson DW. Validity and reliability of the preliminary NINDS neuropathologic criteria for progressive supranuclear palsy and related disorders. J Neuropathol Exp Neurol. 1996; 55:97-105.

77. Irizarry RA, Bolstad BM, Collin F, Cope LM, Hobbs B, Speed TP. Summaries of Affymetrix GeneChip probe level data. Nucleic Acids Res. 2003; 31:e15.

78. Cuadrado-Tejedor M, Garcia-Barroso C, Sanchez-Arias JA, Rabal O, Perez-Gonzalez M, Mederos S, Ugarte A, Franco R, Segura V, Perea G, Oyarzabal J, Garcia-Osta A. A First-in-Class Small-Molecule that Acts as a Dual Inhibitor of HDAC, PDE5 and that Rescues Hippocampal Synaptic Impairment in Alzheimer's Disease Mice. Neuropsychopharmacology. 2016; 42:524-539. 